\title{
TRANSDERMAL DELIVERY OF AN EFFECTIVE NONSTEROIDAL ANTI-INFLAMMATORY DRUGS FOR PAIN MANAGEMENT IN ARTHRITIS
}

\author{
MANJULA D ${ }^{1 *}$, ABHISHEK RAJ ${ }^{1}$, JOSEPHINE LENO JENITA J ${ }^{1}$, SHANAZ BANU ${ }^{2}$ \\ ${ }^{1}$ Department of Pharmaceutics, College of Pharmaceutical Sciences, School of Health Sciences, Dayananda Sagar University, Bengaluru, \\ Karnataka, India. ${ }^{2}$ Department of Pharmacognosy, College of Pharmaceutical Sciences, School of Health Sciences, Dayananda Sagar \\ University, Bengaluru, Karnataka, India. Email: manjula-sps@dsu.edu.in
}

Received: 07 February 2020, Revised and Accepted: 20 April 2020

ABSTRACT

Objective: The current research work has been carried out with the aim to develop a transdermal gel formulation of fenoprofen (a nonsteroidal anti-inflammatory drug used to treat pain associated in arthritis) which would overcome the gastrointestinal-related problems associated with oral administration of the drug. The present study aims at formulating transdermal gels using different concentrations of Carbopol, hydroxypropyl methylcellulose (HPMC), sodium alginate, and guar gum.

Methods: The formulated gels were subjected for various evaluation tests such as clarity, homogeneity, viscosity, drug content, $\mathrm{pH}$, spreadability, and in vitro permeation studies. Drug-polymer interaction was studied by Fourier transmission infrared (FTIR) and differential scanning calorimetry (DSC). The in vitro permeation studies were performed in phosphate buffer 7.4 using Franz diffusion cell.

Results: The FT-IR and DSC studies showed no chemical interaction between drug and polymers used. All the formulated gels showed acceptable physical properties with respect to clarity, homogeneity, viscosity, drug content, $\mathrm{pH}$, and spreadability. Among all the gel formulations, Carbopol gels containing fenoprofen showed good drug release compared to HPMC, sodium alginate, and guar gum. Optimized formulation was further subjected to kinetic studies which showed Higuchi model of drug release. The same formulation showed significant anti-inflammatory and analgesic activity, tested in Wistar albino rats. No signs of erythema, edema, flushing, and papules were observed when skin irritation test was performed. Stability studies under accelerated condition showed satisfactory results for the optimized formulation.

Conclusions: Thus, it was concluded from the results that the optimized formulation showed controlled and slow drug delivery. Animal studies were significant at $\mathrm{p}<0.05$ and 0.001 . The selected formulation was stable at various ambient temperatures.

Keywords: Fenoprofen, Transdermal, Carbopol 940, Hydroxypropyl methylcellulose, Sodium alginate, Guar gum.

(c) 2020 The Authors. Published by Innovare Academic Sciences Pvt Ltd. This is an open access article under the CC BY license (http://creativecommons. org/licenses/by/4. 0/) DOI: http://dx.doi.org/10.22159/ajpcr.2020.v13i7.37058

\section{INTRODUCTION}

Transdermal route has gained accolade as it has several advantages over conventional forms such as, avoids first pass metabolism and lowers gastrointestinal irritation that are associated with oral administration [1]. Easy termination of therapy enables a constant plasma level profile that results in decreased side effects are some other advantages [2]. The release of the drugs from topical preparations depends on the physicochemical properties of the drug and gels employed. Gels for dermatological use have many advantageous properties such as thixotropic, emollient, greaseless, easily spreadable, and easily removable [3]. Gelling agents when mixed with appropriate solvent entangle to form a three-dimensional colloidal network that limits fluid flow by entrapment and immobilization of the solvent molecules. One more advantage of network structure of gels is their resistance to deformation and hence its viscoelastic properties $[4,5]$.

Fenoprofen is a propionic acid derivative with analgesic, antiinflammatory, and antipyretic properties. Oral administration of fenoprofen can cause gastric mucosal damage, respiratory depression, and metabolic acidosis. Its high dose (300-600 mg, 3-4 times daily) causes more plasma fluctuation. To avoid invasive drug therapy and to eliminate frequent dosing with oral administration, a transdermal route has been studied as an alternative dosage form. The low molecular weight, less biological half-life, good analgesic activity, and anti-inflammatory activity make fenoprofen a good candidate for transdermal delivery [6-8].

Hence, the current research was planned to formulate and evaluate gel formulation containing fenoprofen using Carbopol 940, hydroxypropyl methylcellulose (HPMC), sodium alginate, and guar gum. The prepared gels were evaluated for clarity, homogeneity, viscosity, drug content, $\mathrm{pH}$, spreadability, and in vitro permeation studies. Finally, the optimized formulation was further subjected for animal studies and stability studies.

\section{MATERIALS AND METHODS}

Materials

Fenoprofen was obtained as gift sample from D.K Pharma, Mumbai, Carbopol 940, HPMC, sodium alginate, guar gum, ethanol, triethanolamine, and oleic acid were purchased from S.D. Fine Chemicals Limited, Mumbai. All the chemicals obtained were of analytical grade.

\section{Methods}

Fourier transmission infrared (FTIR) studies

The FTIR spectra [9] of the pure drug fenoprofen and its physical mixture with various polymers such as Carbopol 940, HPMC, sodium alginate, and guar gum were recorded using FTIR spectrophotometer (PerkinElmer 1600 series, USA). The samples were prepared by potassium bromide press pellet technique and scanned for the absorbance at $4000-400 \mathrm{~cm}^{-1}$.

\section{Differential scanning calorimetry (DSC)}

The DSC thermograms of the pure drug fenoprofen and its physical mixture with various polymers such as Carbopol 940, HPMC, sodium alginate, and guar gum were recorded using PerkinElmer 1600 series USA instrument, to know any interaction between drug 
and the various polymers used. All the samples were placed in a sealed aluminum pans and scanned for the endothermic peaks. The heating rate selected was from $50^{\circ} \mathrm{C}$ to $300^{\circ} \mathrm{C}$ at an increase of $10^{\circ} \mathrm{C}$ per min [10].

\section{Preparation of transdermal gels}

All the gelling agents were optimized for the optimum concentration at which they formed the gels. It was found that Carbopol, HPMC, sodium alginate, and guar gum formed proper gels at $1 \%, 2 \%, 4 \%$, and $6 \%$ $\mathrm{w} / \mathrm{w}$, respectively.

Carbopol gel was prepared by soaking required quantity of Carbopol 934 in water for a period of $3 \mathrm{~h}$. Then, specified amount of drug was dissolved in ethanol, to this required quantity of propylene glycol was added and stirred. This drug solution was transferred to Carbopol container and stirred for $20 \mathrm{~min}$. Drug containing Carbopol gel was neutralized using triethanolamine with continuous stirring. The dispersion was then allowed to hydrate and swell for $1 \mathrm{~h}$; finally, the desired $\mathrm{pH}$ of 6.8-7 was adjusted using triethanolamine with continuous stirring until a homogeneous gel was formed. Hence, prepared Carbopol gel was allowed to equilibrate for $24 \mathrm{~h}$ at room temperature until further evaluation [11-13].

HPMC, sodium alginate, and guar gum were optimized for polymer concentration. Transdermal gels containing HPMC, sodium alginate, and guar gum were prepared by dispersing $2 \%$ HPMC, $4 \%$ sodium alginate, and $6 \%$ guar gum in water by continuous stirring for a period of $2 \mathrm{~h}$. Fenoprofen was dissolved in ethanol and the drug solution was added gently to various polymeric solutions with continuous stirring until homogeneous gel was formed. Finally, all the gels were allowed to equilibrate at room temperature for $24 \mathrm{~h}$ until further evaluation [14-16]. Detailed formulation is shown in Table 1.

\section{Evaluation of transdermal gels}

Physical appearance and clarity

The prepared fenoprofen gels were inspected visually for their color and transparency [17]. Clarity of various formulations was determined by visual inspection under black and white background and it was graded as turbid +; clear ++; and very clear (glassy) +++.

\section{Homogeneity}

All the formulated gels were tested for homogeneity [18] by visual inspection after the gels have been set in the container. They were tested for their appearance and presence of any aggregates.

\section{Viscosity}

Viscosity [19] was determined using Brookfield viscometer. Viscosity measurements were carried out at room temperature $\left(25-27^{\circ} \mathrm{C}\right)$ using Brookfield Viscometer (Model RVTDV II, Brookfield Engineering Laboratories, Inc., Stoughton, MA).

\section{Measurement of $p H$}

The $\mathrm{pH}[20]$ of various gel formulations was determined using digital $\mathrm{pH}$ meter (Elico). One gram of gel was dissolved in $100 \mathrm{ml}$ distilled water and stored for $2 \mathrm{~h}$. The electrode was inserted into the sample 10 $\mathrm{min}$ before taking the reading at room temperature. The measurement of $\mathrm{pH}$ of each formulation was done in triplicate and average values were calculated.

\section{Drug content}

A specified quantity $(100 \mathrm{mg})$ of formulated gel was taken and dissolved in $100 \mathrm{ml}$ of phosphate buffer $\mathrm{pH}$ 7.4. The volumetric flask containing gel was shaken for a period of $2 \mathrm{~h}$ on mechanical shaker to get absolute solubility of drug. This solution was filtered and estimated spectrophotometrically at $272 \mathrm{~nm}$ using phosphate buffer $\mathrm{pH} 6.8$ as blank [21].

\section{Spreadability}

The spreadability [22] of the gel was determined using the following technique: $0.5 \mathrm{~g}$ gel was placed within a circle of $1 \mathrm{~cm}$ diameter premarked on a glass plate over which a second glass plate was placed. A weight of $500 \mathrm{~g}$ was allowed to rest on the upper glass plate for $5 \mathrm{~min}$. The increase in the diameter due to spreading of the gels was noted. Average of triplicate readings was taken.

\section{In vitro drug release studies}

Drug permeation through rat abdominal skin was carried out after getting approval from the Institutional Animal Ethical Committee, bearing registration number 557/02/C/Committee for the Purpose of Control and Supervision of Experiments on Animals (CPCSEA). It was conducted as per the principles and guidelines of CPCSEA.

Franz diffusion cell was used to carry out in vitro permeation study through rat abdominal skin [23]. The skin was mounted between the compartments of the diffusion cell with stratum corneum facing the donor compartment. One gram of gel containing fenoprofen was placed in the donor cell. Twenty milliliters of phosphate buffer $(\mathrm{pH} 7.4)$ solution were used as receptor medium that was maintained at $37^{\circ} \mathrm{C}$ and magnetically stirred at $300 \mathrm{rpm}$. At appropriate time interval, $1 \mathrm{ml}$ of the sample was withdrawn from the receptor compartment and the same amount of fresh buffer solution was added to maintain sink condition. Simultaneously, a blank diffusion study was carried out in a similar manner using blank gel without fenoprofen. Each experiment was carried out in triplicate. The sample was analyzed spectrophotometrically at a wavelength of $272 \mathrm{~nm}$ and the concentration of drug in receptor compartment was noted.

\section{Mathematical kinetic assessment for drug release mechanisms} Release kinetics is an integral part for the development of a dosage form because, if the kinetics of drug release is known, one can also establish in vitro-in vivo correlation. Mathematical approach is one of the scientific methods to optimize and evaluate the error in terms of deviation in the release profiles of formulated products during the formulation development stage. Mathematical model approaches important in research and development because of its simplicity and their interrelationships may minimize the number of trials in final optimization, thereby improving the formulation development process. The permeation profile of the optimized formulation was fitted to different kinetic models.

Table 1: Formulation of various transdermal gels

\begin{tabular}{|c|c|c|c|c|c|c|c|c|c|}
\hline S. No. & Ingredients & F1 & F2 & F3 & F4 & F5 & F6 & F7 & F8 \\
\hline 1. & Fenoprofen (mg) & 100 & 100 & 100 & 100 & 100 & 100 & 100 & 100 \\
\hline 2. & Carbopol $374(\%)$ & 0.5 & 1 & - & - & - & - & - & - \\
\hline 3. & Hydroxypropyl methylcellulose (gm) & - & - & 1 & 2 & - & - & - & - \\
\hline 4. & Sodium alginate (gm) & - & - & - & - & 3 & 4 & - & - \\
\hline 5. & Guar gum (gm) & - & - & - & - & - & - & 5 & 6 \\
\hline 6. & Oleic acid (\%wrt drug ) & 10 & 10 & 10 & 10 & 10 & 10 & 10 & 10 \\
\hline 7. & Triethanalamine (\%) & 1 & 1 & 1 & 1 & 1 & 1 & & 1 \\
\hline 8. & Water & qst & qst & qst & qst & qst & qst & qst & qst \\
\hline
\end{tabular}

wrt: With respect to, qst: Quantity sufficient to 
Qt versus $\mathrm{t}$ (zero order)

$\log \left(Q_{0}-Q t\right)$ versus $t$ (first order)

Qt versus square root of $t$ (Higuchi)

$\log \%$ Qt versus log t (Korsmeyer-Peppas)

Where, $Q t$ is the amount of drug released at time $t, Q_{0}$ is amount of drug release at time 0 , and $t$ is time in hour.

\section{Animal studies}

All the animal studies were carried out after getting approval from the Institutional Animal Ethical Committee, bearing registration number 557/02/C/CPCSEA. It was conducted as per the principles and guidelines of CPCSEA.

\section{Anti-inflammatory activity}

Wistar albino rats were divided into two groups of six animals each. The ventral surface of the animals was depilated and one group was treated as control and the other group was treated as test. About $2 \%$ $\mathrm{w} / \mathrm{v}$ formalin solution was used as chronic inflammogen to induce inflammation in all animals by subcutaneous route. A mark was made on hind paw just behind tibiotarsal junction so that every time the paw was dipped in the mercury column up to the fixed mark to ensure constant paw volume. The test gel containing the dose of fenoprofen equivalent the body weight of the animal was applied to the animal of test group. The paw volume of all the animals, both control and test groups, was measured using plethysmograph at selected interval of time. Finally, the percentage reduction in edema volume was calculated and the activity of the formulation was statically analyzed by Student's " $\mathrm{t}$ " test [24].

\section{Analgesic activity}

Twelve albino mice were selected and divided into two groups each having six rats. The ventral surface of the animals was depilated and divided into Group 1 (control) and Group 2 (test). A blank gel containing no drug was applied to control group. The selected gel formulation containing the dose of fenoprofen equivalent to body weight was applied on the ventral surface of the test animal group. About $0.6 \% \mathrm{v} / \mathrm{v}$ acetic acid was injected intraperitoneally to all the animals $(1 \mathrm{ml} / 100 \mathrm{~g}$ of body weight of animal) to induce writhes. The number of writhes produced in 15 min was noted. The activity of the formulation was statistically analyzed by Student's "t" test [25].

\section{Skin irritation test}

Skin irritation tests were performed for optimized fenoprofen transdermal gel on the albino rats to find out any irritation problems which could reject its suitability for topical use. Approximately $1 \mathrm{~g}$ of gel was topically applied for the albino rats across a 2 square inch area and was observed for any show any signs of erythema, edema, flushing, and

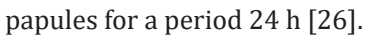

\section{Stability studies of optimized formulation}

Stability studies were conducted according to the ICH guidelines [27] by storing the best selected formulation at room temperature and at $40 \pm 2{ }^{\circ} \mathrm{C} / 75 \% \mathrm{RH}$ in stability chamber for 3 months. The formulation was analyzed for the change in appearance, $\mathrm{pH}$, and drug content by procedure stated earlier.

\section{RESULTS AND DISCUSSION}

\section{FTIR studies}

The principal peaks of fenoprofen were observed at $3647 \mathrm{~cm}^{-1}[\mathrm{~N}-\mathrm{H}$ stretch], $3070 \mathrm{~cm}^{-1}$ [C-H aromatic], $2420 \mathrm{~cm}^{-1}$ [0-H bending], $1423 \mathrm{~cm}^{-1}$ [aromatic $\mathrm{C}=\mathrm{C}$ stretch], and $1566 \mathrm{~cm}^{-1}[\mathrm{C}=0$ stretch. FTIR of physical mixture showed similar peaks indicating no interaction between drug and the polymers employed in formulation. Figs. 1 and 2 show the spectra of pure drug and physical mixture, respectively.

\section{DSC}

The thermogram of pure fenoprofen exhibited a sharp endothermic peak at $125.08^{\circ} \mathrm{C}$ corresponding to its melting point $\left(118-120^{\circ} \mathrm{C}\right)$. Similarly, the thermograms of physical mixtures of fenoprofen with excipients under study exhibited the endothermic peak in the vicinity of its melting point range indicating the absence of any drug excipient interaction. The DSC thermograms are depicted in Fig. 3.

\section{Evaluation of transdermal gels}

Physical appearance and clarity

The prepared fenoprofen gel formulations were transparent in Carbopol 934, white viscous in HPMC, and brownish gummy in sodium alginate and guar gum. All gels were found to be transparent and were free from the presence of particles. Results are tabulated in Table 2 .

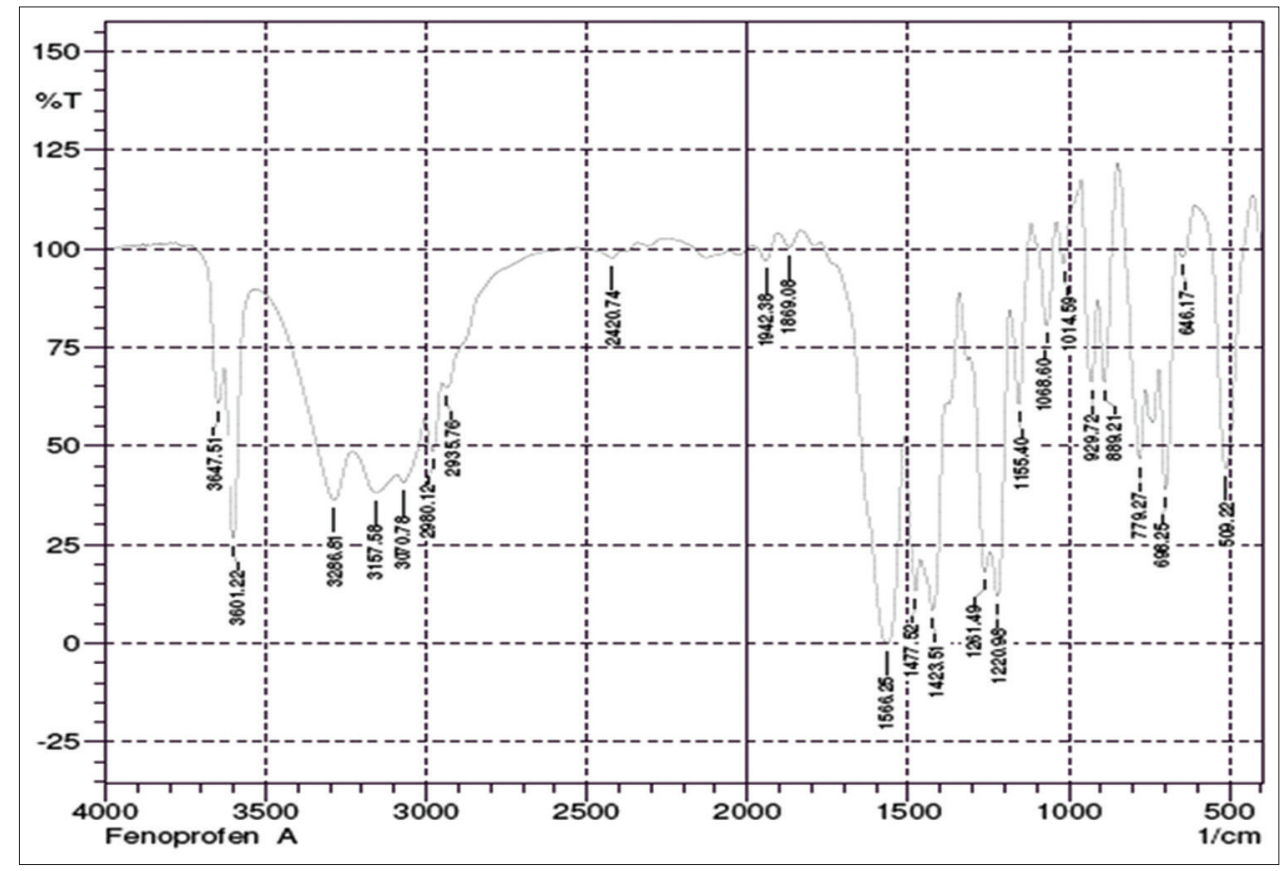

Fig. 1: Fourier transmission infrared of fenoprofen drug alone 


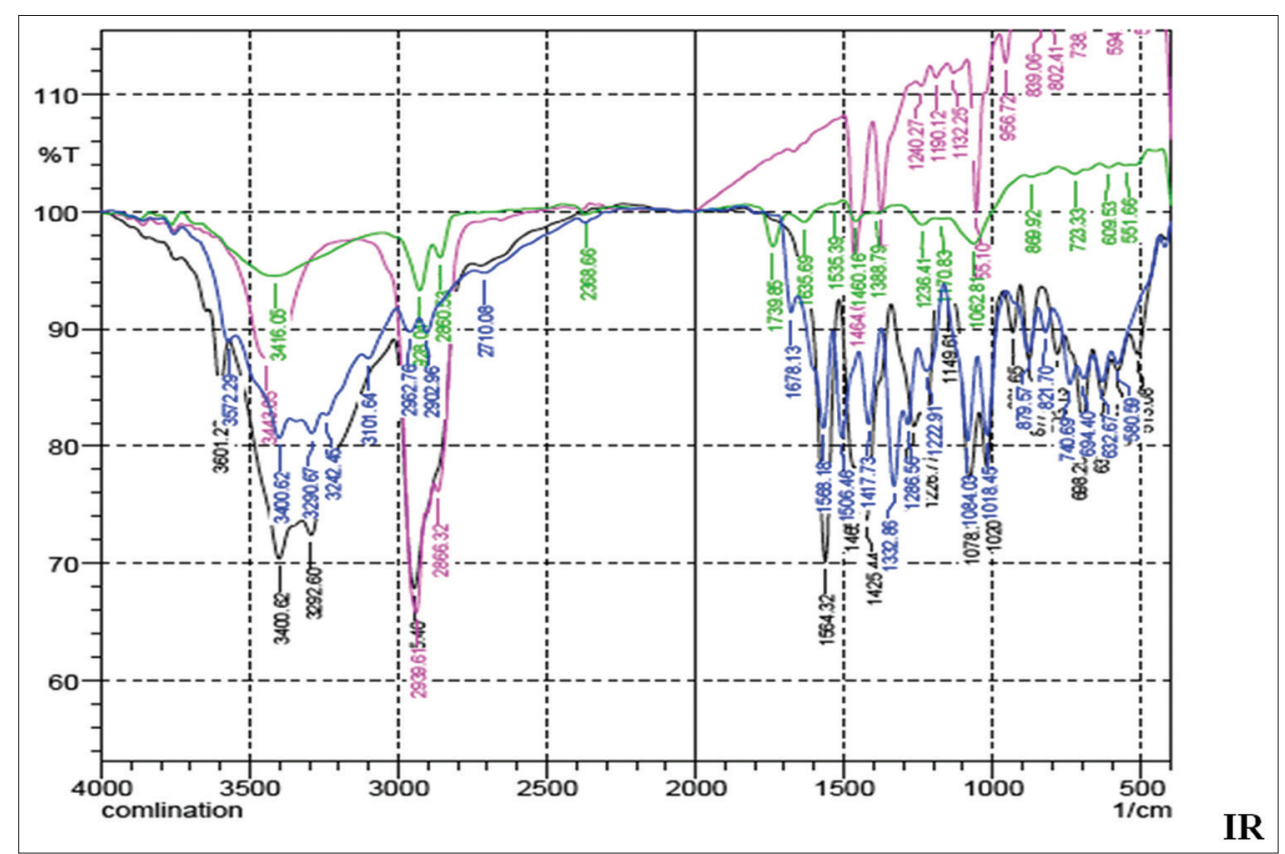

Fig. 2: Fourier transmission infrared spectrum of pure drug fenoprofen with polymers used
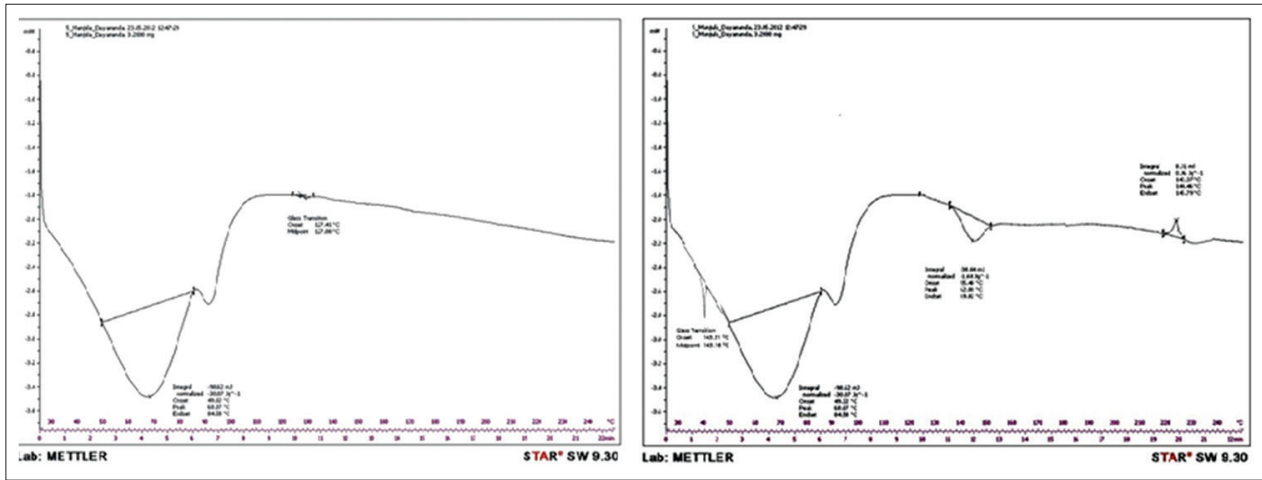

Fig. 3: Differential scanning calorimetry thermograms (a) fenoprofen drug alone (b) physical mixture of drug and polymers used (Carbopol 940, hydroxypropyl methylcellulose, sodium alginate, and guar gum)

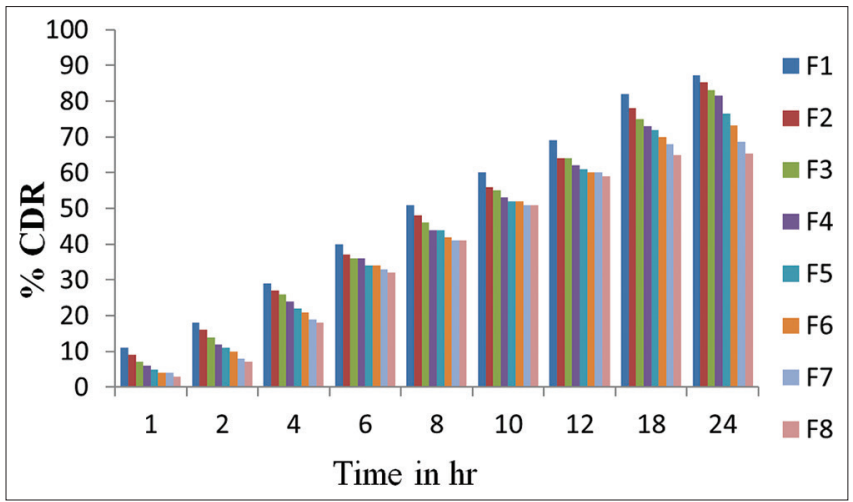

Fig 4: Cumulative drug release from F1 to F8 at different time intervals

\section{Homogeneity}

All the formulations were found to be smooth and homogeneous with the absence of lumps as shown in results (Table 2).

\section{Viscosity}

Viscosity of various formulated gels was found in the range of $0.492 \pm 0.28-0.689 \pm 0.33$ poise, results are depicted in Table 3 .

$p H$

The $\mathrm{pH}$ of the formulated gels was found to be in the range of 5.7-6.9, which lies in the normal $\mathrm{pH}$ range of the skin, so the formulations would not produce any skin irritation. $\mathrm{pH}$ of all formulation is tabulated in Table 3.

\section{Drug content}

The uniformity in drug distribution throughout the gels was estimated by drug content studies. The drug content of the gel formulations was in the range of $82.2 \pm 0.38-93.5 \pm 0.19$ showing content uniformity, Table 3.

\section{Spreadability}

Spreadability diameter for various formulated gels showed good spreadability, i.e., all the gels were easily spreadable. The results are shown in Table 2. 
In vitro drug release studies

In vitro permeation studies of fenoprofen gels containing different concentrations of Carbopol (0.5\% and 1\%), HPMC (1\% and $2 \%)$, sodium alginate $(3 \%$ and $4 \%)$, and guar gum $(5 \%$ and $6 \%)$ were carried out using Franz diffusion cell containing $\mathrm{pH} 7.4$ phosphate buffer as medium and measuring drug concentration by ultraviolet spectrophotometer. The percentage cumulative drug release at different time intervals is depicted in Table 4 and Fig. 4 . The percentage drug release for the formulations containing drug and Carbopol (F1 and F2) was found to be $87.23 \%$ and $85.28 \%$, respectively, for formulations containing drug and HPMC (F3 and F4) was found to be $84.15 \%$ and $83.57 \%$, respectively, for formulations containing drug and sodium alginate (F5 and F6) was found to be $79.49 \%$ and $78.18 \%$, respectively, and that for guar gum formulations (F7 and F8) was found to be $76.56 \%$ and $75.32 \%$, respectively. In general, it was observed that an increase in polymer content was associated with a corresponding decrease in the percentage drug release among Carbopol, HPMC, sodium alginate, and guar gum. This could be attributed to two reasons, first, extensive swelling of the polymer which created a thick gel barrier for drug diffusion [28]. Second, as polymer concentration increased viscosity also increased, which has a negative relation to release of active drug from formulations and its penetration through the diffusion barriers [29]. Thus, both high concentration of polymer and high viscosity compete each other in controlling the release of drug substance from the formulations.

\section{Drug release kinetics}

In vitro drug release data of all formulations from F1 to F8 were fitted to zero-order, first-order, Higuchi, and Korsmeyer-Peppas equations to ascertain the pattern of drug release. The results are depicted in Table 5. When zero-order and first-order drug release kinetics were compared, the $\mathrm{R}^{2}$ values were found to be higher in zero order. Hence, this concluded that all the formulations followed zero-order kinetics. Whereas, in case of mechanism of drug release, between Higuchi and Korsmeyer-Peppas equation, the $\mathrm{R}^{2}$ value was found to be higher in Korsmeyer-Peppas equation and release exponent " $n$ " $<1$. This indicates

Table 2: Evaluation of physical appearance, clarity, homogeneity, and spreadability of various gel formulations

\begin{tabular}{|c|c|c|c|c|}
\hline S. No. & Formulation codes & Physical appearance and clarity & Homogeneity & ${ }^{*}$ Spreadabilitg $\times \mathrm{cm} / \mathrm{s}$ \\
\hline 1. & $\mathrm{~F} 1$ & $\begin{array}{l}\text { White, viscous, transparent } \\
+++\end{array}$ & Homogeneous & $19.12 \pm 0.46$ \\
\hline 2. & $\mathrm{~F} 2$ & $\begin{array}{l}\text { White, viscous, transparent } \\
+++\end{array}$ & Homogeneous & $21.23 \pm 0.35$ \\
\hline 3. & F3 & $\begin{array}{l}\text { White, viscous, translucent } \\
++\end{array}$ & Homogeneous & $26.16 \pm 0.72$ \\
\hline 4. & F4 & $\begin{array}{l}\text { White, viscous, translucent } \\
++\end{array}$ & Homogeneous & $29.42 \pm 0.88$ \\
\hline 5. & F5 & $\begin{array}{l}\text { Brownish, gummy } \\
++\end{array}$ & Homogeneous & $24.56 \pm 0.21$ \\
\hline 6. & F6 & $\begin{array}{l}\text { Brownish, gummy } \\
++\end{array}$ & Homogeneous & $25.17 \pm 0.89$ \\
\hline 7. & F7 & $\begin{array}{l}\text { Light brown, gummy } \\
++\end{array}$ & Homogeneous & $22.65 \pm 0.69$ \\
\hline 8. & F8 & $\begin{array}{l}\text { Light brown, gummy } \\
++\end{array}$ & Homogeneous & $24.32 \pm 0.87$ \\
\hline
\end{tabular}

+++: Excellent, ++: Good. ${ }^{*}$ Average of triplicate readings

Table 3: Evaluation of viscosity, pH, drug content, and flux of various gel formulations

\begin{tabular}{lllll}
\hline S. No. & Formulation codes & $*$ Viscosity (poise) & ${ }^{*} \mathbf{p H}$ & ${ }^{*}$ Drug content $(\%)$ \\
\hline 1. & F1 & $0.562 \pm 0.76$ & $7.3 \pm 0.29$ & $93.5 \pm 0.19$ \\
2. & F2 & $0.593 \pm 0.81$ & $7.5 \pm 0.55$ & $92.1 \pm 0.24$ \\
3. & F3 & $0.613 \pm 0.25$ & $6.9 \pm 0.81$ & $89.5 \pm 0.96$ \\
4. & F4 & $0.689 \pm 0.33$ & $7.1 \pm 0.80$ & $88.6 \pm 0.87$ \\
5. & F5 & $0.552 \pm 0.91$ & $6.8 \pm 0.35$ & $85.9 \pm 0.39$ \\
6. & F6 & $0.587 \pm 0.53$ & $6.3 \pm 0.86$ & $85.3 \pm 0.47$ \\
7. & F7 & $0.492 \pm 0.28$ & $6.5 \pm 0.47$ & $82.2 \pm 0.38$ \\
8. & F8 & $0.498 \pm 0.76$ & $6.7 \pm 0.51$ & $82.8 \pm 0.59$ \\
\hline
\end{tabular}

*Average of triplicate readings

Table 4: Percent drug release of various gels containing fenoprofen

\begin{tabular}{|c|c|c|c|c|c|c|c|c|}
\hline \multirow[t]{2}{*}{ Time in $h$} & \multicolumn{8}{|c|}{ Formulation codes } \\
\hline & F1 & F2 & F3 & F4 & F5 & F6 & F7 & F8 \\
\hline 1 & 11.12 & 9.12 & 7.62 & 6.13 & 5.23 & 4.13 & 4.55 & 3.57 \\
\hline 2 & 18.22 & 16.31 & 14.16 & 13.54 & 13.22 & 12.26 & 11.12 & 11.78 \\
\hline 4 & 29.13 & 27.25 & 26.83 & 24.25 & 24.15 & 21.37 & 19.23 & 18.82 \\
\hline 6 & 40.42 & 37.13 & 36.19 & 36.44 & 34.27 & 34.43 & 33.34 & 32.91 \\
\hline 8 & 51.34 & 48.65 & 46.53 & 44.29 & 44.35 & 42.52 & 41.45 & 41.47 \\
\hline 10 & 60.32 & 56.32 & 55.76 & 53.71 & 52.57 & 52.61 & 51.54 & 51.73 \\
\hline 12 & 69.71 & 64.55 & 64.62 & 62.13 & 61.62 & 60.26 & 60.53 & 59.52 \\
\hline 18 & 82.27 & 78.23 & 75.85 & 73.64 & 72.73 & 70.37 & 68.62 & 65.24 \\
\hline 24 & 87.23 & 85.28 & 84.15 & 83.57 & 79.49 & 78.18 & 76.56 & 75.32 \\
\hline
\end{tabular}

The standard deviation of all formulations was found to be in the range of $\pm 0.19- \pm 0.32$ 


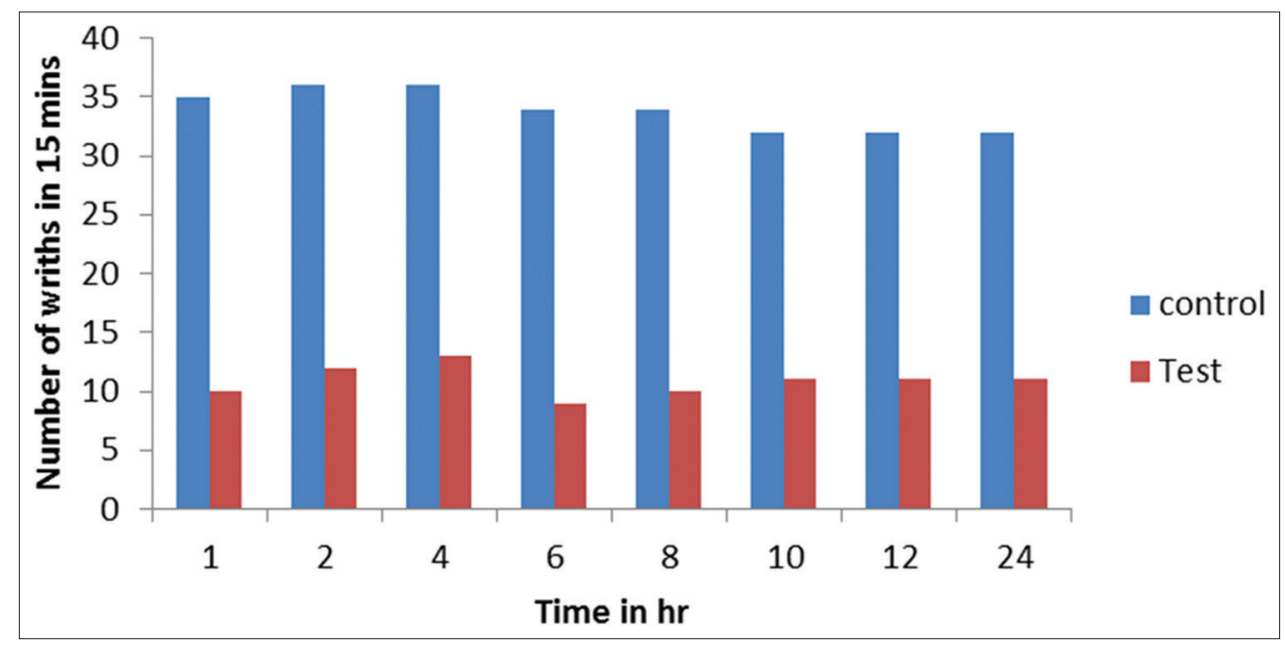

Fig. 5: Analgesic activity of F2 formulation

Table 5: Drug release kinetics of formulations F1 to F8

\begin{tabular}{|c|c|c|c|c|}
\hline \multirow[t]{3}{*}{ Formulation codes } & \multicolumn{4}{|c|}{ Release kinetics } \\
\hline & Zero order & First order & Korsmeyer-Peppas & Higuchi diffusion model \\
\hline & $\mathbf{R}^{2}$ & $\mathbf{R}^{2}$ & $\mathbf{R}^{2}$ & $\mathbf{R}^{2}$ \\
\hline F1 & 0.992 & 0.965 & 0.993 & 0.967 \\
\hline $\mathrm{F} 2$ & 0.995 & 0.961 & 0.996 & 0.969 \\
\hline F3 & 0.994 & 0.959 & 0.993 & 0.972 \\
\hline F4 & 0.993 & 0.962 & 0.999 & 0.974 \\
\hline F6 & 0.996 & 0.958 & 0.997 & 0.951 \\
\hline F7 & 0.995 & 0.961 & 0.991 & 0.967 \\
\hline F8 & 0.993 & 0.960 & 0.992 & 0.971 \\
\hline
\end{tabular}

Table 6: Anti-inflammatory activity of F2 formulation

\begin{tabular}{lllll}
\hline S. No. & $\begin{array}{l}\text { Time } \\
\text { in h }\end{array}$ & $\begin{array}{l}\text { Control } \\
\text { mean }\end{array}$ & \multicolumn{2}{c}{ Test formulation } \\
\cline { 4 - 5 } & & & Mean & \% reduction in edema \\
\hline 1. & 1 & 0.279 & 0.248 & 10.4 \\
2. & 2 & 0.342 & 0.319 & 5.53 \\
3. & 4 & 0.373 & 0.301 & 11.59 \\
4. & 6 & 0.409 & 0.298 & 21.93 \\
5. & 8 & 0.431 & 0.278 & 32.21 \\
6. & 10 & 0.481 & 0.251 & 44.55 \\
7. & 12 & 0.533 & 0.218 & 56.89 \\
8. & 24 & 0.652 & 0.203 & 63.8 \\
\hline
\end{tabular}

Table 7: Skin irritation test of F2 formulation

\begin{tabular}{lllll}
\hline S. No. & Time in h & \multicolumn{3}{l}{ F1 formulation } \\
\cline { 3 - 5 } & & F & P & E \\
\hline 1. & 1 & $-v e$ & $-v e$ & $-v e$ \\
2. & 2 & $-v e$ & $-v e$ & $-v e$ \\
3. & 4 & $-v e$ & $-v e$ & $-v e$ \\
4. & 6 & $-v e$ & $-v e$ & $-v e$ \\
5. & 8 & $-v e$ & $-v e$ & $-v e$ \\
6. & 10 & $-v e$ & $-v e$ & $-v e$ \\
7. & 12 & $-v e$ & $-v e$ & $-v e$ \\
8. & 24 & $-v e$ & $-v e$ & $-v e$ \\
\hline
\end{tabular}

-ve: No allergic manifestation observed, F: Flushing of skin, P: Papules and wheels, E: Erythema and edema

that all the formulations followed non-Fickian diffusion. Hence, it was concluded that all the formulations followed zero-order drug release with non-Fickian diffusion [30].

\section{Animal studies}

Since F2 formulation was found to be good compared to other formulations with respect to appearance, clarity, homogeneity, viscosity, spreadability, and also controlled drug release was observed in this formulation, so this particular formulation was further subjected to animal studies.

\section{Anti-inflammatory activity of F2 formulation}

Anti-inflammatory activity of $\mathrm{F} 2$ formulation showed $63.8 \%$ reduction of formalin-induced paw edema at the end of $24 \mathrm{~h}$, as shown in Table 6. The data were analyzed by P-STAT package where F2 showed a significant anti-inflammatory activity at $\mathrm{p}<0.05$.

\section{Analgesic activity of F2 formulation}

Same formulation F2 was subjected for analgesic activity by acetic acid-induced writhing method for a period of $24 \mathrm{~h}$. The data analyzed with P-STAT package was found to be significant at $\mathrm{p}<0.05$ and 0.001 . The analgesic activity is depicted in the form of bar graph of number of writhes per 15 min plotted against time, as shown in Fig. 5.

\section{Skin irritation test of F2 formulation}

The animals subjected for hypersensitivity studies did not show any signs of erythema, edema, flushing, and papules for a period of $24 \mathrm{~h}$ (Table 7).

\section{Stability studies}

Stability studies of the selected formulation (F2) showed no significant change in its physical appearance, $\mathrm{pH}$, and drug content when stored at room temperature and at $40 \pm 2{ }^{\circ} \mathrm{C} / 75 \% \mathrm{RH}$ for a period of 3 months.

\section{CONCLUSIONS}

On the whole, it can be concluded that the various gels containing fenoprofen were found to be satisfactory with respect to physic 
chemical properties. There was also controlled drug release seen as the polymer concentration increased. Animal studies were significant at $\mathrm{p}<0.05$ and 0.001 . The selected formulation was stable at various ambient temperatures. Further, there is a scope for pharmacokinetic studies and its correlation with pharmacodynamics activity in higher animals

\section{ACKNOWLEDGMENT}

The authors are thankful to the management and Dean of College of Pharmaceutical Sciences, Dayananda Sagar University, for providing an opportunity to carry out this research work.

\section{AUTHORS' CONTRIBUTIONS}

Manjula D and Abhishek Raj designed the research work, Josephine Leno Jenita helped in animal studies, and Shanaz Banu assisted in drafting the manuscript.

\section{CONFLICTS OF INTEREST}

The authors have declared that they have no conflicts of interest with respect to current research.

\section{REFERENCES}

1. Kikwai L, Babu RJ, Prado RA, Kolot A, Armstrong CA, Ansel JC, et al. In vitro and in vivo evaluation of topical formulations of Spantide II. AAPS Pharm Sci Tech 2005;6:565-72.

2. Jalwal P, Jangra A, Dahiya R, Sangwan Y, Saroha R. A review on transdermal patches. Pharma Res 2010;3:139-49.

3. Suhonen MT, Bouwstra JA, Urtti A. Chemical enhancement of percutaneous absorption in relation to stratum corneum structural alterations. J Control Release 1999;59:149-61.

4. Kumar L, Verma R. In vitro evaluation of topical gel prepared using natural polymer. Int J Drug Deliv 2010;2:58-63.

5. Tettey-AmlaloIn RN. In vitro Release of Ketoprofen from Proprietary and Extemporaneously Manufactured Gels. Grahamstown: Rhodes University; 2005. p. 92-3.

6. British Pharmacopoeia Commission. $5^{\text {th }}$ ed., Vol. 1 . TSO (The Stationery Office); 2007. p. 855.

7. Tilo G, Emer S, Garret A. Anti-inflammatory and analgesic agents; pharmacotherapy of Gout. In: Laurence LB, editor. The Pharmacological Basis of Therapeutics. New York: McGraw Hill; 2011. p. 954-1004.

8. Budavari S. Hydroxypropyl methyl cellusose. In: The Merck Index. $12^{\text {th }}$ ed. Whitehouse station, New Jersey: Merck and Co.; 1996.

9. Manjula D, Shabaraya AR, Shyale S. Transdermal delivery of fenoprofen: Preparation, evaluation and in vitro release. World J Pharm Res 2015;4:1142-53

10. Sainz MC, Chantres JR, Elorza B. DSC study of action of phenylbutazone on phospholipid phase transitions. Int J Pharm 1993;91:1-8.

11. Acharya A, Dhakal P, Khadka D. Formulation and evaluation of transdermal gel of lornoxicam and its delivery by passive and inotophoresis method: A comparative study. Int J Pharm Sci Res 2016;7:810-8

12. Kaur D, Raina A, Singh N. Formulation and evaluation of carbopol
940 based glibenclamide transdermal gel. Int J Pharm Pharm Sci 2014;6:434-40.

13. Ubaid M, Ilyas S, Mir S, Khan AK, Rashid R. Formulation and in vitro evaluation of carbopol 934-based modified clotrimazole gel for topical application. An Acad Bras Cienc 2016;88:2303-17

14. Al-Saidan SM, Krishnaiah YS, Chandrasekhar DV, Lalla JK, Rama B. Formulation of an HPMC gel drug reservoir system with ethanolwater as a solvent system and limonene as a penetration enhancer for enhancing in vitro transdermal delivery of nicorandil. Skin Pharmacol Physiol 2004; 17:310-20.

15. Tanwar YS, Jain AK. Formulation and evaluation of topical diclofenac sodium gel using different gelling agent. Asian J Pharmaceut Res Health Care 2012;4:1-6.

16. Monica S, Gautami J. Design and evaluation of topical hydrogel formulation of diclofenac sodium for improved therapy. Int J Pharm Sci Res 2014;5:1973-80

17. Shivhare UD, Jain KB, Mathur VB, Bhusari KP, Roy AA. Formulation development and evaluation of diclofenac sodium gel using water soluble polyacrylamide polymer. Dig $\mathrm{J}$ Nanomater Biostruct 2009;4:285-90.

18. Gupta A, Mishra AK, Singh AK, Gupta V, Bansal P. Formulation and evaluation of topical gel of diclofenac sodium using different polymers. Drug Invent Today 2010;2:250-3.

19. Gendy AM, Jun HW, Kassem AA. In vitro release studies of flurbiprofen from different topical formulations. Drug Dev Ind Pharm 2002;48:823-31.

20. Nair R, Sevukarajan M, Mohammed B, Kumar J. Formulation of microemulsion based vaginal gel in vitro and in vivo evaluation. Pharm Lett 2010;2:99-105.

21. Manjula D, Shabaraya AR, Srikanth P, Suma R. Design and evaluation of transdermal films containing ketoprofen for the treatment of arthritis. J Drug Deliv Ther 2012;2:117-21.

22. Shinde U, Pokharkar S, Modani S. Design and evaluation of microemulsion gel system of nadifloxacin. Indian J Pharm Sci 2012:74:237-47.

23. Manjula D, Shabaraya AR, Shyale S. Topical delivery of fenoprofen proliposomes: Preparation, evaluation and in vitro release. Int J Pharm Sci Invent 2014;3:6-12.

24. Manjula D, Shabaraya AR, Shyale S, Jenita JL. Preparation and evaluation of monolithic transdermal therapeutic systems containing fenoprofen for the treatment of arthritis. Int. J Pharm Sci Rev Res 2012;13:61-5

25. Lalan BK, Hiray RS, Ghongane BB. Evaluation of analgesic and antiinflammatory activity of extract of Holoptelea integrifolia and Argyreia speciosa in animal models. J Clin Diagn Res 2015;9:1-16.

26. Omale J, Ajidahun BS. Evaluation of acute dermal irritation and wound contraction by Gymnema sylvestre and Datura metel extracts in rats. Am J Biomed Life Sci 2014;2:83-8.

27. Manjula D, Shabaraya AR, Shyale S. Formulation, characterization and in vitro release of proliposomes for topical delivery of aceclofenac. J Pharm Res 2014:8:674-9.

28. Li J, Mooney DJ. Designing hydrogels for controlled drug delivery. Nat Rev Mater 2016;1:16071.

29. Muhr AH, Blanshard JM. Diffusion and interaction in gels and solutions. J Chem Phys 1993;98:1012-26

30. Rajasekaran A, Arulkumaran G, Ramasamy A. Formulation and evaluation of topical herbal gel for the treatment of arthritis in animal model. Braz J Pharm Sci 2016;52:493-507. 